\title{
Upregulated expression of vascular endothelial growth factor in proliferative diabetic retinopathy
}

\author{
Jacob Pe'er, Robert Folberg, Ahuva Itin, Hadassah Gnessin, Itzhak Hemo, Eli Keshet
}

\begin{abstract}
Aims/Background-Vascular endothelial growth factor (VEGF) is a hypoxia induced angiogenic factor. Recent studies have shown that high levels of VEGF accumulate in the vitreous of patients with proliferative diabetic retinopathy (PDR). The purpose of the present study was to identify the retinal cells that upregulate VEGF expression in human PDR patients representing progressive stages of retina deterioration.

Methods-Thirteen formalin fixed and paraffin embedded enucleated eyes with PDR were used (eyes were enucleated because of being blind and painful as a result of neovascular glaucoma). Thin retina sections were hybridised in situ with a VEGF specific probe, to identify cells producing VEGF mRNA.
\end{abstract}

Results-All eyes with PDR showed upregulated expression of VEGF mRNA, specifically in the cells of the neurosensory retina. VEGF expression was upregulated in all three nuclear layers - namely, the ganglion cell layer, the inner nuclear layer, and the outer nuclear layer. However, in each patient, VEGF producing cells were mostly distributed in a different layer, or even confined to a specific region in that layer. For example, expression by the outer nuclear layer was mostly detected in detached (presumably hypoxic) regions of the retina.

Conclusions-Progression of PDR is distinguished by a sustained, upregulated expression of VEGF by the neurosensory retina. Cells in all retina layers can potentially contribute to augmented VEGF production. The restricted population of VEGF producing cells in each case is likely to represent cells residing in ischaemic regions of the retina. Thus, VEGF may function as a linking factor between retinal ischaemia and PDR associated neovascularisation.

(Br $\mathcal{F}$ Ophthalmol 1996; 80: 241-245)

Intraocular neovascularisation is one of the major causes of blindness worldwide. ${ }^{1}$ Diabetic retinopathy, and especially its proliferative stage, is the second leading cause of legal blindness, and the leading cause of blindness in people 25 to 74 years of age, in the United States. ${ }^{2}$

The retina has the highest oxygen requirements of any tissue in the body. Hence, insufficient perfusion and the resultant hypoxia are considered to be a major stimulus for compensatory neovascularisation. Michaelson ${ }^{3}$ was the first to hypothesise that the ischaemic retina elaborates a hypoxia inducible angiogenic factor. Ashton ${ }^{4}$ later extended the theory by postulating that the vasoformative material produced by the ischaemic retina not only induces retinal neovascularisation, but may also diffuse anteriorly to stimulate new vessel formation in the iris.

Many investigators have searched for Michaelson's postulated angiogenic factor. In recent years, several candidate factors were suggested to play a role in proliferative diabetic retinopathy (PDR) pathogenesis. Insulin-like growth factor 1 (IGF-1) and its receptors were detected in the vitreous and retina, with elevated levels of IGF-1 detected in the vitreous of eyes with PDR. ${ }^{56}$ Fibroblast growth factor (FGF), both acidic FGF and basic FGF, were found in eyes with PDR. ${ }^{78}$ Transforming growth factor $\beta$ (TGF- $\beta$ ), platelet derived growth factor (PDGF), and tumour necrosis factor $\alpha$ (TNF- $\alpha),{ }^{9}$ were also suggested to play a role in ocular angiogenesis. More recently, it was shown that increased vitreous levels of vascular endothelial growth factor (VEGF) are found in PDR patients. ${ }^{10-12}$

The question of which of these factors, if any, functions to link retinal ischaemia with the pathological angiogenic response in PDR patients, however, has remained unanswered. We have previously shown that VEGF is hypoxia inducible and may mediate hypoxia initiated angiogenesis, in general. ${ }^{13}$ These observations were later extended to show that induction of experimental retinal ischaemia in animal models leads to upregulated VEGF expression. ${ }^{14} 15$ These findings prompted us to examine whether VEGF expression is upregulated during natural progression of human PDR, to identify the VEGF producing cells at progressive stages of PDR development, and to determine whether VEGF is specifically induced in ischaemic regions of the retina.

\section{Material and methods}

The files of the FC Blodi Eye Pathology Laboratory were searched for paraffin blocks of enucleated eyes with the histopathological diagnosis of proliferative diabetic retinopathy and neovascular glaucoma. Cases were excluded if the eyes were phthisical or were complicated by endophthalmitis. Importantly, no postmortem specimens were included in this study. Thirteen cases described clinically as 'blind and painful' qualified for this study. As a control, five eyes with choroidal or ciliary body melanoma, but with no detectable neovascularisation, were analysed in parallel. 
Enucleated eyes were fixed in $10 \%$ neutral buffered formalin for 2-7 days. Five mm thick sections at the pupillary-optic nerve (P-O) level were collected on poly (L) lysine coated glass slides, refixed, dehydrated in graded ethanol solutions, and further processed for in situ hybridisation as follows. Sections were pretreated successively with $0.2 \mathrm{M} \mathrm{HCl}$, pronase $(0.125 \mathrm{mg} / \mathrm{ml}), 4 \%$ paraformaldehyde, and acetic anhydride in triethanolamine buffer. Hybridisation was carried out at $50^{\circ} \mathrm{C}$ overnight in a solution containing $50 \%$ (vol $/ \mathrm{vol}$ ) formamide/ $0.3 \mathrm{M} \mathrm{NaCl}$ and ${ }^{35} \mathrm{~S}$-labelled RNA probe $\left(2 \times 10^{8} \mathrm{cpm} / \mathrm{ml}\right)$. A $590 \mathrm{bp} \mathrm{cDNA} \mathrm{frag-}$ ment that includes most of the coding region of human VEGF $_{165}$ and subcloned in a PBS vector (Stratagene), was used as a VEGF specific probe. The linearised plasmid served as a template for synthesis of an ${ }^{35} \mathrm{~S}$-labelled complementary RNA in either the antisense or sense orientation (using T3 or T7 RNA polymerase). The cRNA was fragmented by a mild alkaline treatment to a size of $50-150$ bp before use for in situ hybridisation. Post-hybridisation washing was performed under stringent conditions that included an incubation at $50^{\circ} \mathrm{C}$ for more than 14 hours in $50 \%$ formamide $/ 0.3 \mathrm{M} \mathrm{NaCl}$, and a 30 minute incubation at $37^{\circ} \mathrm{C}$ with RNAase $(20 \mathrm{mg} / \mathrm{ml})$. Autoradiography was performed using Kodak NTB-2 nuclear track emulsion (Kodak, Rochester, NY, USA) with exposure for 5-9 days. Slides were examined by light microscope, using bright field (to see the black grains) as well as dark field (by which the grains look bright).

\section{Results}

The clinical details of the 13 patients included in the study are summarised in Table 1 . There were 10 males and three females aged 19 to 81 years, all with diabetes mellitus. There were eight right eyes and five left eyes. All were enucleated because they were blind and painful due to neovascular glaucoma. Histologically, all had proliferative diabetic retinopathy and neovascular glaucoma. Nine had partial or total retinal detachment. Eleven patients showed evidence of intraocular haemorrhage, to a certain extent. Eight patients were previously treated by laser retinal

Table 1 Clinical features of blind painful eyes removed for proliferative diabetic retinopathy and neovascular glaucoma

\begin{tabular}{|c|c|c|c|c|c|c|}
\hline $\begin{array}{l}\text { Patient } \\
\text { No }\end{array}$ & $\begin{array}{l}\text { Age } \\
\text { (years) }\end{array}$ & Sex & Eye & History & Haemorrhages & Other findings \\
\hline $\begin{array}{l}1 \\
2 \\
3\end{array}$ & $\begin{array}{l}77 \\
33 \\
55\end{array}$ & $\begin{array}{l}\mathbf{F} \\
\mathbf{M} \\
\mathbf{M}\end{array}$ & $\begin{array}{l}\mathbf{R} \\
\mathbf{R} \\
\mathbf{L}\end{array}$ & $\begin{array}{l}\text { DM - at } 48 \text { years } \\
\text { IDDM } \\
\text { DM - at } 29 \text { years }\end{array}$ & $\begin{array}{l}\text { Subretinal } \\
\text { Hyphaema, vitreous, subretinal } \\
\text { Hyphaema, subretinal }\end{array}$ & $\begin{array}{l}\text { Aphakia } \\
\text { PRP }\end{array}$ \\
\hline $\begin{array}{l}4 \\
5\end{array}$ & $\begin{array}{l}26 \\
24\end{array}$ & $\begin{array}{l}\mathbf{M} \\
\mathbf{M}\end{array}$ & $\begin{array}{l}\mathbf{L} \\
\mathbf{L}\end{array}$ & $\begin{array}{l}\text { DM } \\
\text { IDDM }\end{array}$ & Las & $\begin{array}{l}\text { NVD, PRP } \\
\text { PRP }\end{array}$ \\
\hline 6 & 58 & $M$ & $\mathbf{R}$ & DM & $\begin{array}{l}\text { Hyphaema, retinal, subretinal, } \\
\text { subhyaloid }\end{array}$ & PRP \\
\hline $\begin{array}{l}7 \\
8\end{array}$ & $\begin{array}{l}42 \\
19\end{array}$ & $\begin{array}{l}\mathbf{M} \\
\mathbf{F}\end{array}$ & $\begin{array}{l}\mathbf{R} \\
\mathbf{R}\end{array}$ & $\begin{array}{l}\text { DM } \\
\text { DM }\end{array}$ & $\begin{array}{l}\text { Subretinal } \\
\text { Hyphaema, vitreous, subretinal, } \\
\text { suprachoroid }\end{array}$ & PRP \\
\hline $\begin{array}{r}9 \\
10 \\
11 \\
12 \\
13\end{array}$ & $\begin{array}{l}72 \\
56 \\
81 \\
41 \\
59\end{array}$ & $\begin{array}{l}\mathbf{F} \\
\mathbf{M} \\
\mathbf{M} \\
\mathbf{M} \\
\mathbf{M}\end{array}$ & $\begin{array}{l}\mathbf{L} \\
\mathbf{R} \\
\mathbf{R} \\
\mathbf{R} \\
\mathbf{L}\end{array}$ & $\begin{array}{l}\text { DM } \\
\text { IDDM } \\
\text { DM } \\
\text { DM } \\
\text { DM }\end{array}$ & $\begin{array}{l}\text { Vitreous, subretinal } \\
\text { Hyphaema, vitreous } \\
\text { Subretinal, vitreous } \\
\text { Vitreous, subretinal, intraretinal }\end{array}$ & $\begin{array}{l}\text { PRP } \\
\text { NVD, PRP } \\
\text { PRP }\end{array}$ \\
\hline
\end{tabular}

$\mathrm{DM}=$ diabetes mellitus (type not stated); IDDM=insulin dependent $\mathrm{DM} ; \mathrm{PDR}=$ proliferative diabetic retinopathy; $P R P=$ panretinal photocoagulation (laser); $N V D=$ neovascularisation of optic disc. photocoagulation. The specimens examined represented progressive stages in severity of the disease, as evident also by different degrees of retinal disorganisation (see below).

To identify cells expressing VEGF mRNA, in situ hybridisation analysis was performed, using sections of whole globes. Preliminary experiments indicated that the mRNA preservation in these specimens is adequate for detection by in situ hybridisation analysis, even after long term storage (certain specimens have been stored as paraffin blocks for longer than 5 years).

In comparison with control eyes (eyes with no intraocular neovascularisation), where VEGF mRNA was either undetectable or barely detectable, all cases of PDR showed strong in situ hybridisation signals. Control hybridisations of adjacent serial section with a VEGF specific probe in the 'sense' orientation showed no signal above background (data not shown). The retina was the only tissue in the eye in which expression of VEGF was observed. Four representative examples of retina with PDR are shown in Figure 1.

Comparative analysis between PDR patients with respect to the pattern of VEGF expression allowed us to make the following generalisations: (1) Abundant VEGF expression was detected in all three nuclear layers of the retina - namely, in the ganglion cell layer (GC), in the inner nuclear layer (INL), and in the outer nuclear layer (ONL). Strikingly, however, in each patient VEGF was predominantly produced by cells residing in one (or two) particular cell layers. Furthermore, the cellular layer producing the bulk of VEGF mRNA differed from one case of PDR to the other. For example, in patient 4 VEGF was mostly produced by cells residing in the ganglion cell layer (Fig 1A), in patient 10 VEGF expression was mostly confined to the INL (Fig 1B), and in patient 8 both INL expression and ONL expression were detected (Fig 1D). (2) In some cases, the territory of VEGF production was further restricted to certain regions within a single layer. Examples can be seen in Figure 1A, where ganglion cells in a particular region express more VEGF than ganglion cells in its flanking regions, and in Figure 1D, where a limited subset of INL cells contribute to VEGF production significantly more than neighbouring INL cells. (3) Regarding the relation between VEGF production and the status of retinal disorganisation, we note that upregulated VEGF expression is already detectable in relatively early stages of PDR progression, distinguished by the grossly normal appearance of the retina (for example, case presented in Figs $1 \mathrm{~A}$ and $1 \mathrm{~B}$ ), continues at stages where the structural organisation of the retina is severely impaired (for example, case shown in Fig 1C) and still persist in the fully deranged retina (for example, in the 'funnel-shaped' retinal detachment shown in Fig 1D). Expression of VEGF in the ONL was only detected in cases of retinal detachment (see, for example in Fig 1D). 

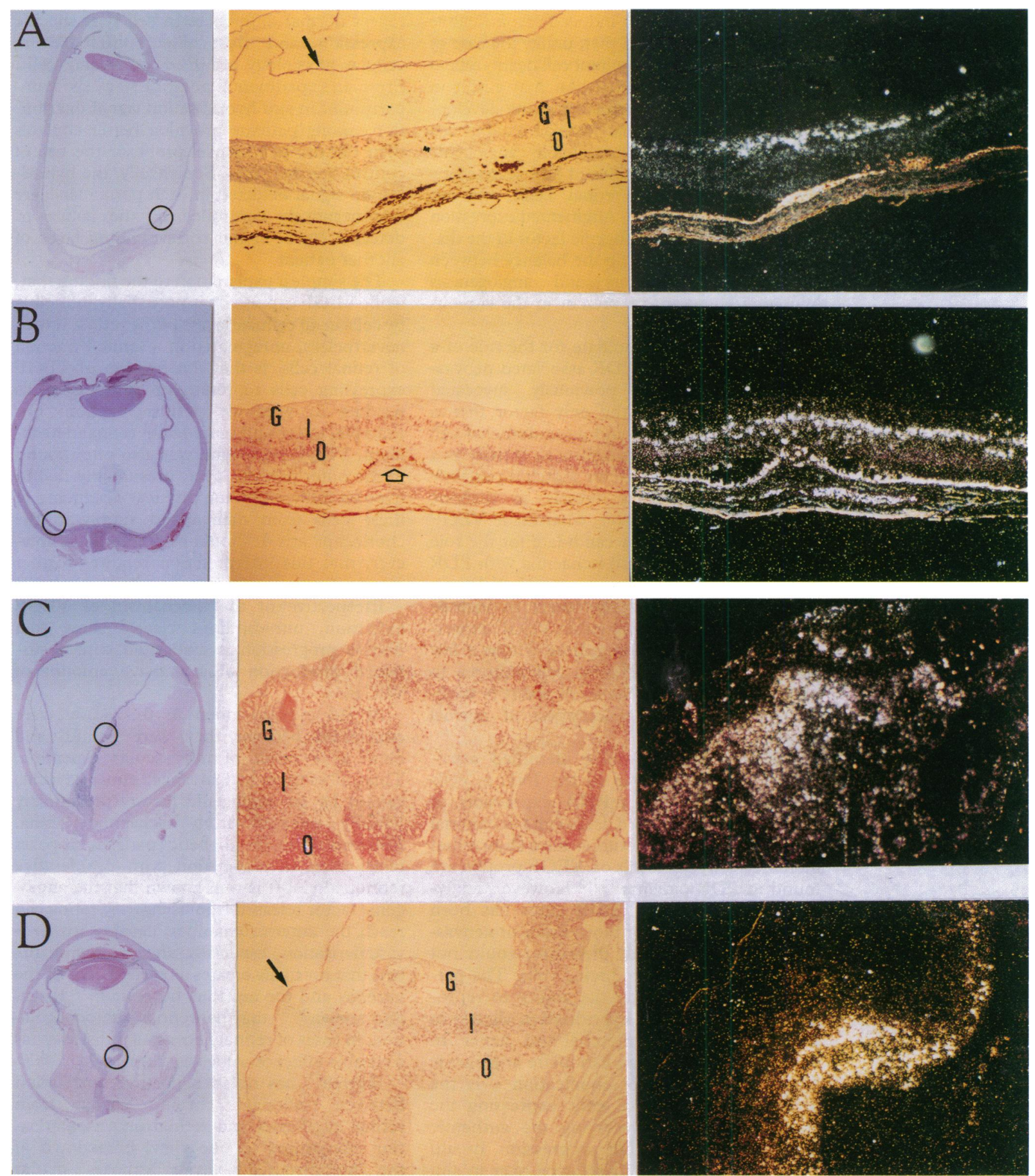

Figure 1 Expression of vascular endothelial growth factor (VEGF) $m R N A$ in the retina of patients with proliferative diabetic retinopathy (PDR).

Specimens shown are from four PDR patients representing different degrees of retinal disorganisation. Images show signals obtained from in situ hybridisation of whole enucleated globes with a VEGF specific probe. The cases shown in $(A-D)$ are of patients $4,10,6$, and 8, respectively $(T a b l e ~ 1)$. Left panels show a general view of the enucleated globe, stained with haematoxylin and eosin (X1.25 magnification). Middle and right panels show (at a higher (X500) magnification) a region of the retina from an adjacent section hybridised with the VEGF specific probe (a region grossly corresponding to the encircled region in the left panels). Images were photographed under both bright field (middle images) and dark field (right images) illuminations. The white staining over the pigmented epithelium, seen in the dark field image of $(A)$ and $(B)$ does not reflect an autoradiographic signal, but is due to pigment staining. Arrows point at neovascular membranes. The open arrow in $(B)$ points at an old laser hit. $G=$ ganglion cell layer; $I=$ inner nuclear layer. $O=$ outer nuclear layer.

\section{Discussion}

Early vascular changes in PDR include degeneration and loss of pericytes ${ }^{16}$ and basement membrane thickening. ${ }^{17}$ Both changes are late consequences of the systemic metabolic abnormalities associated with prolonged hyperglycaemia. The early changes in the retinal vasculature may eventually lead to a compromised blood flow and to severe ischaemia of the sensory retinal tissue. Subsequent steps in PDR pathogenesis are believed to represent a compensatory angiogenic response leading to excessive formation of abnormally leaking vessels. ${ }^{18}$

Following Michaelson's ${ }^{3}$ and Ashton's ${ }^{4}$ initial hypothesis that retinal neovascularisation 
is triggered by a hypoxia induced vasoformative factor, Wise ${ }^{19}$ suggested that, unlike the case of retinal infarction and resultant cell death, retinal venous or capillary obstruction may result in retinal circulatory impedance and the development of a relative cellular hypoxia without cell death. Thus, hypoxia inducible angiogenic factor is likely to be produced and secreted by the affected sensory retinal cells over an extended period of time. Augmented expression of hypoxia induced angiogenic factor in the diabetic patient may then tip the balance between angiogenesis stimulators and angiogenesis inhibitors known to be present in the vitreous and retina. ${ }^{20-24}$

VEGF is a good candidate for the role of a factor responsible for PDR associated neovascularisation. Among previously suggested candidates, VEGF is the only factor that is both a secreted factor and an endothelial cell specific mitogen. Furthermore, its activity as a vascular permeability factor matches perfectly the findings of leaky vessels in diabetic retinopathy. ${ }^{25-31}$ However, what made VEGF an even more attractive candidate for the role of a factor linking retinal ischaemia with PDR associated angiogenesis, were our initial findings, ${ }^{13}$ later extended by others to include additional tissues, showing that VEGF expression is dramatically upregulated within a few hours of exposing different cell cultures to hypoxia, and that mRNA levels revert to background levels upon resumption of normal oxygen supply.

Recent studies ${ }^{14} 15$ have identified astrocytes and cells residing in the INL as cells upregulating VEGF mRNA expression in experimentally induced ischaemia in animal models. Other recent studies have shown that increased vitreous levels of VEGF protein are found in PDR patients. ${ }^{10-12}$ However, analysis of natural human PDR cases has been limited to analysis of vitreous fluids or neovascular membranes and, therefore, could not identify the VEGF producing cells. The present study - exploiting the ability to reproduce efficient in situ hybridisation signals in archival pathological material and, hence, to identify cells expressing candidate angiogenic factors at the time of enucleation - is the first to identify retinal cells expressing the angiogenic factor, preserving the authentic cellular contexts of PDR progression. In situ analysis of mRNA was preferred over in situ immunodetection of the encoded protein because the localisation of the mRNA unequivocally identifies the producer cells, whereas VEGF is known to be secreted and might also be sequestered elsewhere in the tissue. ${ }^{32}$

If the assumption that VEGF expression in PDR is upregulated in response to retinal hypoxia is correct, then it is anticipated that in different patients, different populations of retinal cells will be the major producers of VEGF mRNA. Indeed, we found that in each patient, VEGF producing cells were mostly distributed in a different layer, or even confined to a specific region within a single layer. Clearly, these patterns of expression cannot reflect normal differences in cell type specific expression, and must reflect differences in cellular physiology of VEGF producing cells. From an experimental point of view, the comparison of in situ hybridisation signal distribution among patients provided better controls than the use of a 'sense' probe or the use of control 'normal' eyes. Specifically, the hybridisation signal detected in each particular layer was negatively controlled by the failure to detect a signal in the corresponding layer of another patient.

The simplest explanation to the finding that, while VEGF expression is potentially inducible by cells in all cellular layers of the retina, it was, nevertheless, upregulated in a limited fraction of retinal cells, is that the fraction of VEGF expressing cells represent in each case cells residing in a poorly perfused region. For example, in eyes presented with retinal detachment, VEGF expression was also often found in the outer nuclear layer, presumably due to hypoxia inflicted by the physical distancing of these cells from their blood supply in the choriocapillaris. It should be pointed out, however, that this interpretation requires further proof.

Irrespective of the mechanism of VEGF induction, our findings clearly show that disease progression is associated with a sustained production of a massive amount of VEGF.

All 13 eyes included in this study were enucleated because they were painful and blind as a result of neovascular glaucoma. Thus, all of them had advanced rubeosis iridis, caused by an angiogenic factor (presumably VEGF) released from ischaemic retina. Rubeosis iridis in diabetic patients appears most often in association with proliferative retinopathy. ${ }^{33}$ It is well known that the angiogenic factor released from ischaemic retina can reach the anterior chamber, causing iris neovascularisation, especially after removing the lens that normally creates a barrier between the vitreous and the aqueous humour. ${ }^{34} 35$ It was also shown ${ }^{36} 37$ that panretinal photocoagulation, in cases of retinal neovascular disease, has a curable effect on rubeosis iridis.

Hayreh $^{38}$ has noted a positive correlation between prolonged chronic leakage from retinal capillaries and retinal neovascularisation. According to one view, breakdown of the blood-retinal barrier exposes ocular tissues and vessels to 'abnormal compounds' that induce neovascularisation. Since VEGF also acts as a vascular permeability factor, it seems more likely that increased vascular leakage is not the cause of retinal neovascularisation, but rather a consequence of excessive VEGF production.

In conclusion, our findings regarding upregulated expression of VEGF $\mathrm{mRNA}$ in the nuclei of sensory cells residing in hypoxic microenvironments of the PDR retina, in conjunction with previous findings regarding high levels of VEGF protein in the vitreous of eyes with $P D R,{ }^{10-12}$ strongly suggest that VEGF might function as one of the factors linking retinal ischaemia and angiogenesis in PDR. 
Presented in part at the ARVO meeting, Sarasota, Florida, May 1994.

The study was supported in part by a grant from the Juvenile Diabetes Foundation International (to EK).

1 Garner A. Ocular angiogenesis. Int $\mathcal{F}$ Exp Pathol 1986; 28: 249-309.

2 National Society to Prevent Blindness. Vision problems in the US. Data analysis, definitions, data sources, detailed data tables, analysis, interpretation. New York: National Society to Prevent Blindness, 1980.

3 Michaelson IC. The mode of development of the vascular system of the retina, with some observations on its signifisystem of the retina, with some observations on its significance for certain retinal

4 Ashton N. Retinal vascularization in health and disease. Am f Ophthalmol 1957; 44: 7-17.

5 Grant M, Russell B, Fitzgerald C, Merimelt J. Insulin-like growth factors in vitreous. Studies in control and diabetic subjects with neovascularization. Diabetes 1986; 35 subjects

6 King GL, Goodman AD, Buzney S, Moses A, Kahn CR. Receptors and growth-promoting effects of insulin and insulin-like growth factors on cells from bovine retinal insulin-like growth factors on cells from bovine reting

7 Siralingam A, Kenney J, Brown GC, Benson WE, Donoso L. Basic fibroblast growth factor levels in the vitreous of patients with proliferative diabetic retinopathy Arch Ophthalmol 1990; 108: 869-72.

8 Fredj-Reggrobelet D, Baudouin C, Negre F, Caruelle JP, Gastaud P, Lapalus P. Acidic FGF and other growth factors in preretinal membranes from patients with diabetic retinopathy and proliferative vitreoretinopathy. Ophthalmic Res 1991; 23: 154-61.

9 Wiedemann P. Growth factors in retinal diseases: proliferative vitreoretinopathy, proliferative diabetic retinopathy and retinal degeneration. Surv Ophthalmol 1992; 36: 373-84.

10 Adamis AP, Miller JW, Bernal MT, D'Amico DJ, Folkman $\mathrm{J}$, Yeo TK, et al. Increased vascular endothelial growth factor levels in the vitreous of eyes with proliferative diabetic retinopathy. $A m$ f Ophthalmol 1994; 118: 445-50.

11 Malecaze F, Clamens S, Simorre-Pinatel V, Mathis A Chollet $\mathrm{P}$, Favard C, et al. Detection of vascular endothelial growth factor-like activity in proliferative diabetic lial growth factor-like activity in proliferative
retinopathy. Arch Ophthalmol 1994; 112: 1476-82.

12 Aiello LP, Avery RL, Arrigg PG, Keyt BA, Jampel HD, Shah ST, et al. Vascular endothelial growth factor in ocular fluid of patients with diabetic retinopathy and othe retinal disorders. $N$ Engl f Med 1994; 33: 1480-7.

13 Shweiki D, Itin A, Soffer D, Keshet E. Vascular endothelial growth factor induced by hypoxia may mediate hypoxiainitiated angiogenesis. Nature 1992; 359: 843-5.

14 Miller JW, Adamis AP, Shiima DT, D'Amore PA, Moulto $\mathrm{RS}$, O'Reill MS, et al. Vascular endothelial growth
factor/vascular permeability factor is temporally and spatially correlated with ocular angiogenesis in a primate model. Am ₹ Pathol 1994; 145: 574-84.

15 Pe'er J, Shweiki D, Itin A, Hemo I, Gnessin H, Keshet E. Hypoxia-induced expression of vascular endothelia growth factor (VEGF) by retinal cells is a common factor in neovascularizing ocular disease. Lab Invest 1995; 72: 638-45.

16 Addison DJ, Garner A, Ashton N. Degeneration of intramural pericytes in diabetic retinopathy. $B r$ Med $\mathcal{F} 1970$; 1 : mural peri.

17 Ashton N. Vascular basement membrane changes in diabetic retinopathy. $\mathrm{Br} \mathcal{F}$ Ophthalmol 1974; 58: 344-66.

18 Sebag J, McMeel JW. Diabetic retinopathy. Pathogenesis and the role of retina-derived growth factor in angiogenesis. Surv Ophthalmol 1986; 30: 377-84.

19 Wise GN. Retinal neovascularization. Trans Am Ophthalmol Soc 1956; 52: 729-826.

$20 \mathrm{Chen} \mathrm{CH}$, Chen SC. Angiogenic activity of vitreous and retinal extract. Invest Ophthalmol Vis Sci 1980; 19: 596-602.

21 Glazer BM, D'Amore PA, Michels RG, Patz Z, Fenselau A. Demonstration of vasoproliferative activity from mammalian retina. 7 Cell Biol 1980; 84: 298-304.

22 Lutty GA, Chandler C, Bennett A, Fait C, Patz A. Presence of endothelial cell growth factor activity in normal and diabetic eyes. Curr Eye Res 1986; 5: 9-17.

23 McIntosh LC, Gaal JC, Forrester JV. Serum-induced proliferation of retinal capillary endothelial cells is inhibited in the presence of retinal extract. Curr Eye Res 1989; 8: 871-81.

24 Bensaid M, Malecaze F, Bayard F, Tauber JP. Opposing effects of basic fibroblast growth factor and transforming growth factor- $\beta$ on the proliferation of cultured bovine retinal capillary endothelial cells (BREC). Exp Eye Res retinal capillary

25 Gospodarowicz D, Abraham JA, Schilling J. Isolation and characterization of vascular endothelial mitogen produced by pituitary-derived folliculo stellate cells. Proc Natl Acad Sci USA 1989; 86: 7311-5

26 Keck PJ, Hauser SD, Krivi G, Sanzo K, Warren T, Feder J, Connolly DT. Vascular permeability factor, an endothelial cell mitogen related to PDGF. Science 1989; 246: 1309-12.

27 Connolly DT, Heuvelman DM, Nelson R, Olander J, Eppley B, Delfino J, et al. Tumor vascular permeability Eppley B, Delfino J, et al. Tumor vascular permeability f Clin Invest 1989; 84: 1470-8.

28 Leung DW, Cachianes G, Kaung WJ, Goeddel DV, Ferrara $\mathrm{N}$. Vascular endothelial growth factor is a secreted angiogenic mitogen. Science 1989; 246: 1306-9.

29 Plouet J, Schilling J, Gospodarowicz D. Isolation and characterization of a newly identified endothelial cell mitogen produced by AtT-20 cells. EMBO ₹ 1989; 8: 3801-6.

30 Conn G, Soderman DD, Schaeffer MT, Wile M, Hatcher V, Thomas KA. Purification of a glycoprotein vascular endothelial cell mitogen from a rat glioma-derived cell line. Proc Natl Acad Sci USA 1990; 87: 1323-7.

31 Ferrara N, Houck K, Jakeman L, Leung DW. Molecular and biological properties of the vascular endothelial growth factor family of proteins. Endocrine Rev 1992; 13: 18-32.

32 Dvorak HF, Sioussat TM, Brown LF, Berse B, Nagy JA, Sortel A, et al. Distribution of vascular permeability factor (vascular endothelial growth factor) in tumors: concentration in tumor blood vessels. F Exp Med 1991; 174: tion in $1275-8$.

33 Gartner S, Henkind P. Neovascularization of the iris (rubeosis iridis). Surv Ophthalmol 1978; 22: 291-312.

34 Rice TA, Michels RG, Maguir MG, Rice EF. The effect of lensectomy on the incidence of iris neovascularization and neovascular glaucoma after vitrectomy for diabetic retinopathy. Am $\mathcal{f}$ Ophthalmol 1983; 95: 1-1 1 .

35 Poliner LS, Christianson DJ, Escoffery RF, Kolker AE, Gordon ME, Neovascular glaucoma after intracapsular and extracapsular cataract extraction in diabetic patients. Am f Ophthalmol 1985; 100: 637-43.

36 Little HL, Rosenthal AR, Dellaporta H, Jacobson DR. The effect of pan-retinal photocoagulation on rubeosis iridis. Am $\mathcal{F}$ Ophthalmol 1976; 81: 804-9.

37 Loatikainen L. Preliminary report on effect of retinal panphotocoagulation on rubeosis iridis and neovascular glaucoma. Br f Ophthalmol 1977; 61: 278-84.

38 Hayreh SS. Ocular neovascularization. An hypothesis. Int Ophthalmol 1980; 2: 27-32. 